\title{
Labor Market Frictions and Moving Costs of the Employed and Unemployed
}

\author{
Tyler Ransom
}

\begin{abstract}
Search frictions and switching costs may grant monopsony power to incumbent employers by reducing workers' outside options. This paper examines the role of labor market frictions and moving costs in explaining worker flows across US labor markets. Using data on non-college-educated workers from the Survey of Income and Program Participation (SIPP), I estimate a dynamic model of job search and location choice. I find that moving costs are substantial and that labor market frictions primarily inhibit the employed. Reducing these frictions would result in a higher wage elasticity of labor supply to the firm and could reduce employer monopsony power.
\end{abstract}

JEL Classification: C35, E32, J22, J61, J64, R23

Keywords: Migration, Job search, Dynamic discrete choice

Acknowledgments: Tyler Ransom is an assistant professor of economics at the University of Oklahoma and a research affiliate at IZA. Contact: Department of Economics, University of Oklahoma, 308 Cate Center Dr, Room 158 CCD1, Norman, OK 73072. E-mail: ransom@ou.edu. Telephone: +1 405325 2861. A previous version of this paper was circulated under the title, "The Effect of Business Cycle Fluctuations on Migration Decisions" and was the first chapter of my PhD dissertation. The author would like to thank Peter Arcidiacono, Patrick Bayer, V. Joseph Hotz, and Arnaud Maurel for their helpful comments and encouragement throughout the duration of this project. Martha Stinson and Gary Benedetto provided expert knowledge and invaluable assistance with the SIPP data and methodology, and Christopher Timmins generously provided locational price data. The author would also like to thank participants at the Princeton Conference on Monopsony in the Labor Market, and in particular Evan Starr and my discussant Ted To. This paper also benefited from conversations with Jared Ashworth, Esteban Aucejo, Patrick Coate, Christos Makridis, Kyle Mangum, Ekaterina Jardim, Michael Ransom, Seth Sanders, Juan Carlos Suárez Serrato, and various other conference and seminar participants. All errors are the author's.

An Online Appendix can be found at http://jhr.uwpress.org/.

Data Availability: The primary data source of this paper is a confidential data set housed at the U.S. Census Bureau. The data can be obtained by submitting a research proposal to the Census Bureau through a Federal Statistical Research Data Center Administrator (https://www.census.gov/about/adrm/fsrdc/contact.html). Code and publicly available auxiliary data that can be used to replicate the results of this paper is located at https://doi.org/10.5281/zenodo.4495571. The author commits to providing guidance about obtaining the confidential data and using it to replicate the results.

Disclosure statement: Funding from National Science Foundation grant SES-11-31897 and the University of Oklahoma College of Arts and Sciences is gratefully acknowledged. Any opinions and conclusions expressed herein are my own and do not necessarily represent the views of the U.S. Census Bureau. All results have been reviewed to ensure that no confidential information is disclosed. No IRB approval was required to conduct this research. 


\section{Introduction}

Migration is widely considered to be a key indicator of labor market health, for two reasons. First, it is understood to be the primary way by which local labor markets adjust to shocks (Topel, 1986; Blanchard and Katz, 1992; Yagan, 2014). Second, lower levels of migration may indicate a less competitive labor market: when workers are unable or unwilling to move, their outside options are diminished and employers can compensate them below their market value (Ransom, 1993; Fox, 2010), or recruit only within the local area (Karahan and Rhee, 2017). ${ }^{\mathrm{i}}$

In this paper, I develop and estimate a dynamic structural model that incorporates switching costs and search frictions - two commonly cited sources of monopsony power. In the model, workers choose labor markets in which to live, but face frictions in obtaining employment and costs to moving locations or entering or exiting the labor force. Moving costs depend on employment status and frictions depend on both employment status and local labor market conditions. These dimensions of migration have not yet been looked at in the literature. I use the model to compute moving costs by employment status and to examine workers' relocation behavior in response to local labor market shocks or to a moving subsidy (for example Moretti, 2012; H.R. 2755, 2015). I also examine how firm switching costs relate to monopsony power by simulating a related model of workers' choices over firms.

I study individual migration, employment, and labor force transitions across U.S. metropolitan areas over the period 2004-2013. My primary data source is confidential panel data collected by the Survey of Income and Program Participation (SIPP). My sample consists of prime-age white men who are not college educated. The large coverage of the SIPP allows me to observe many moves and to accurately observe the conditions of many local labor markets. The SIPP also contains detailed information on demographic characteristics and labor market 
experience.

The econometric model characterizes locations in three dimensions which enter workers' utility functions and govern their decision making. The three dimensions are market and nonmarket amenities, expected earnings, and expected employment. Each worker has common preferences for a location's market amenities (for example, climate), but workers may value nonmarket amenities differently (for example, proximity to family). Earnings and employment differ across workers based on differences in their observable and unobservable characteristics. For unobservables, workers are also classified into two discrete types which differ in terms of wages, employment, and switching costs.

The model specifies locational choice and labor supply as a discrete choice dynamic programming problem. ${ }^{\text {ii }}$ Search frictions enter the model in a reduced form, where those who choose to supply labor are assigned to employment according to a weighted lottery. The employment probability depends on local labor market conditions as well as the worker's previous location decision and individual characteristics. ${ }^{\text {iii }}$ In order to estimate the model, I utilize recent developments in the estimation of large-state-space dynamic discrete choice models. By making use of conditional choice probabilities (CCPs) and the property of finite dependence, I tractably estimate a model that includes many alternative choices and uncertainty in choice outcomes.

A key component of my analysis is that search frictions differ based on current employment and residence status. That is, in the style of Burdett and Mortensen (1998), the employed and non-employed face different search processes. This paper builds on their framework by also allowing the search process to differ based on whether a worker has recently moved from another labor market. Descriptive statistics show that these dimensions are important to migration 
and job search. I show that the non-employed are much more likely than the employed to move. ${ }^{\text {iv }}$ I also show that employed movers are much less likely to remain in employment than employed stayers. On the other hand, employment probabilities are about the same for non-employed movers and stayers.

Using estimates of worker preferences and productivity, I calculate each type of worker's willingness to move under alternative scenarios such as a local labor market shock or a government-provided moving subsidy. Migration responses to changes in the local labor market are similar to a spatial labor supply elasticity in the situation where workers have few withinlocation employment options. ${ }^{\mathrm{v}}$

The estimated parameters imply that moving costs are substantial, and that labor market frictions are especially burdensome for the employed. I estimate the moving cost to the average person to have a present value on the order of $\$ 400,000$. Although large, this estimate is in line with many other studies. The primary reason for the large magnitude is that there is a weak empirical relationship between expected earnings and observed moves. With regard to search frictions, the descriptive finding of reduced job offer arrivals for employed movers continues to hold in the structural model after allowing for employment to depend on unobserved worker ability. Thus, search frictions act as an additional hindrance to migration for the employed. In contrast, the non-employed are equally likely to receive an offer whether or not they move, so search frictions are less binding to their migration behavior and their outside options are not affected by moving.

I use the structural model estimates to study migration responses to local labor market shocks, and to a government move subsidy. Employed workers are more likely to stay in a place experiencing a local economic downturn, but less so if the economic downturn is nationwide. 
The opposite is true for the unemployed, who are more likely to move in response to a local economic downturn. If the government were to offer a $\$ 10,000$ moving subsidy to the unemployed (for example, as proposed in the American Worker Mobility Act; H.R. 2755, 2015), my model predicts that there would be low take-up rates $(\approx 3 \%-5 \%)$, with even lower take-up rates among those who are already in their home location. ${ }^{\mathrm{vi}}$ Response to the subsidy differs by the conditions of the local labor market and the desirability of the location.

To more precisely illustrate the impact of switching costs on monopsony power, I simulate a dynamic model of worker choices over firms. The model shares features of Card et al. (2018) and Lamadon, Mogstad, and Setzler (2019), but adds firm switching costs. I calibrate the parameter values of the model to match the estimates of my empirical model and moments in the SIPP. I use the model to compute the wage elasticity of labor supply to individual firms, following Hirsch et al. (2019). When switching costs are infinite, labor supply is perfectly inelastic. At the level of firm switching observed in the SIPP, the elasticity of labor supply is about 1 for the average firm. Further reducing switching costs would result in higher labor supply elasticities. These results indicate that when workers face costs to switching firms, this market imperfection grants employers monopsony power.

\section{Data and Stylized Facts about Migration and Unemployment}

I now introduce the main data sources used in the paper and presents stylized facts about moving costs and labor market frictions that motivate the structural model.

\section{II.A Data}

The main data source is the 2004 and 2008 panels of the Survey of Income and Program Participation (SIPP). I supplement the SIPP with data on location characteristics and local labor market conditions. 


\section{II.A.1 The SIPP}

The SIPP is a longitudinal survey of a stratified random sample of residents of the United States, administered by the United States Census Bureau. Respondents are interviewed every four months over a four- or five-year span. Each four-month period is referred to as a wave. Survey respondents are asked questions regarding their living arrangements, labor force participation, earnings, assets, government program participation, migration, and education, among many other topics. Within each wave, respondents provide additional information on many of these activities at the monthly level.

In order to preserve confidentiality, the data used here-which make use of detailed residence location and earnings that are not top-coded — are not released publicly by the SIPP and are only available through the Census Research Data Center (RDC) Network.vii Furthermore, the confidential version of the SIPP is linked via the respondent's social security number to Internal Revenue Service (IRS) and Social Security Administration (SSA) administrative data on annual earnings, employment history, government program participation, and social security benefits receipts. I make use of this link to create work experience profiles based on the administrative data that are less vulnerable to survey recall error.

The SIPP's longitudinal structure, combined with its large-sized cross-section makes it useful for studying migration and labor supply behavior. Because it is a survey, it can distinguish between unemployment and labor force detachment - two effects that are conflated in studies that use administrative data such as tax records (Yagan, 2014; Schluter and Wilemme, 2018; Schmutz and Sidibé, 2019).

The main disadvantages of the SIPP are two-fold. First, its panels are relatively short—four to five years in length. Second, attrition rates in the SIPP are higher than in other longitudinal 
surveys. However, there is evidence that its high attrition rates do not bias labor market outcomes (Zabel, 1998).

\section{II.A.2 Individual variables}

With the data in hand, I now introduce the outcome and explanatory variables used in the analysis. There are three main outcomes of interest: location; labor force and employment status (employed, unemployed, or out of the labor force); and monthly earnings if employed.

Labor force participation and unemployment are defined in terms of strength of attachment, as follows. Labor force participants are those who have a full-time job or who are seeking a fulltime job. Those who are self-employed or who voluntarily work part-time are excluded from my definition of the labor force. Unemployment is defined here as labor force participation that is not full-time employment. Full-time employment is defined as working 35 or more hours per week for all weeks in the survey month.

Although the definitions I use for labor force participation and unemployment are unconventional, I use these definitions because my model focuses on the relationship between migration and labor market frictions. People who are only weakly attached to the labor force are by definition less likely to move for employment reasons. Later on, I show that my descriptive results are not sensitive to these unconventional definitions of labor force status and employment.

Focusing on full-time employment (rather than any employment) has additional benefits. First, full-time employees are most likely to be employed throughout the year, which more closely matches the time horizon of the model. Second, the SIPP does not measure hours worked at the monthly level - only at the wave level. Thus, measuring earnings at the hourly level is more difficult. I focus on full-time jobs because these jobs are most likely to be salaried, and an hourly earnings measure does not appropriately capture marginal labor productivity for salaried workers. 
I define monthly earnings as the sum of earnings across all jobs in the survey month. I deflate earnings by cost of living in the location as described later in this section. All monetary figures throughout this paper are expressed in constant 2000 dollars unless otherwise noted.

The primary explanatory variables are work experience, age, and birth location. I indirectly use additional demographic variables such as education level, sex, and race/ethnicity to determine the estimation subsample. I create work experience from IRS records as an annualized measure of the sum of all quarters worked. I similarly construct age from the SSA data by comparing the calendar year and month with the birth year and month. Respondents report their state or country of birth in Wave 2 of each SIPP panel.

\section{II.A.3 Geographical variables}

I define locations as cities (Core Based Statistical Areas or CBSAs). ${ }^{\text {viii }}$ In order to maintain tractability, I restrict to the 35 cities that are most frequently observed in the SIPP. I construct an additional 20 residual synthetic locations to ensure that the choice set is geographically exhaustive. These synthetic locations are grouped into two population bins (small and medium) based on population. Online Appendix Table A4 contains a complete list of all 55 locations. A map of the 35 cities can be found in Online Appendix Figure A1.

Modeling a large number of locations is essential to capturing the actual locational choice alternatives that individuals face. I focus on cities rather than states because business cycles are heterogeneous across cities, even within the same state. ${ }^{\text {ix }}{ }^{9}$ Furthermore, because many cities cross state boundaries, focusing on cities more closely characterizes the actual local labor market. Modeling the largest cities is also a parsimonious way of categorizing the choice set: $43 \%$ of the US population resides in the 30 largest cities (CBSAs). ${ }^{\mathrm{x}}$ Finally, the residual locations are divided into population categories because there is evidence in the urban economics literature 
that a variety of labor market outcomes differ systematically by city size due to agglomeration economies, thick market effects, human capital externalities, and labor market competition (Glaeser and Maré, 2001; Gould, 2007; Baum-Snow and Pavan, 2012; Hirsch et al., 2019). Breaking out the residual categories by city size is a parsimonious way of capturing these effects.

Beyond the geographical definition of location, I also make use of the population, unemployment rate, and price level of the worker's city. Population is defined as the 2000 Census population level in the county of residence, aggregated to the CBSA level. It is used to divide locations that are smaller than the top 35 cities. The unemployment rate is taken at the county level from the Bureau of Labor Statistics (BLS) Local Area Unemployment Statistics data series and aggregated to the CBSA level, weighting by county population.xi This variable is used in the model to inform individuals about their employment prospects in each location. I merge these city characteristics using a crosswalk that maps counties to CBSAs. Further details on data sources can be found in Online Appendix Table A3.

Following a number of papers in the literature, I spatially deflate earnings using the American Chamber of Commerce Research Association's Cost of Living Index (ACCRACOLI). ${ }^{x i i}$ I follow Baum-Snow and Pavan (2012) and Winters (2009). Further details on the construction of this index can be found in Online Appendix Section A.7.

\section{II.A.4 Estimation subsample}

I estimate the model using non-Hispanic white men of prime working age (ages 18-55 at the beginning of the survey) who have completed school and who do not have a bachelor's degree. I remove college graduates because their job search process across space is much different than that of non-college graduates (Balgova, 2018). I focus on men of a particular education level, race, and ethnicity in order to form a homogeneous sample, and because migration is a household decision 
where the male head's employment prospects are more likely to dictate a geographical move. ${ }^{\text {xii }}$ However, I show later that my basic stylized facts about employment and migration hold for other demographic groups. The final estimation subsample comprises 16,648 men each averaging 3.03 annual observations.

Tables 1 and 2 list descriptive statistics for the estimation subsample. The average individual in the sample is 42 years old and has 23 years of work experience. Living near one's location of birth is common, with almost $75 \%$ of the sample residing in their state of birth. Table 2 lists the migration statistics in the sample, which contains 568 movers who make 653 moves.

I use four annual observations for the 2004 panel-the interview month of waves $2,5,8$, and 11 - to measure location, labor market outcomes, and individual characteristics. The 2008 Panel is slightly longer, so I use the same waves in addition to wave 14 . The entire dataset spans the years 2004-2013, but any given individual can only appear in at most five of those years. Most of the sample has at least three observations. For more details on sample selection and construction of key variables, see Online Appendix Section A.6 and Online Appendix Table A1.

\section{II.B Stylized Facts about Migration and Unemployment}

With the data in hand, I now present three stylized facts about migration and unemployment that will show motivating evidence on the two sources of monopsony power that I focus on: moving costs and search frictions.

First, the non-employed are more geographically mobile than the employed. Second, employed workers who move are much less likely to become employed after the move than employed workers who stay. This phenomenon is restricted to employed movers; non-employed movers are just as likely to get a job as non-employed stayers. Third, the employment prospects of non-employed workers are relatively worse during local economic downturns, compared to employed workers. 
For expositional reasons, I illustrate these facts using publicly available SIPP data on all workers in the United States, as opposed to the confidential data on non-Hispanic white men that I use in the structural model. In all cases, employment is defined as described previously.

Figure 1 shows that, across multiple distances, the non-employed move more frequently than the employed. The difference amounts to about a 50\% higher mobility rate for across-state moves, and about a $30 \%$ higher mobility rate for within-state, across-county moves. ${ }^{\text {xiv }}$

To see if movers and stayers tend to have different employment outcomes, I estimate a simple linear probability model. The left-hand side variable is an indicator for full-time employment in the current period. The right-hand side variables include race-cross-gender dummies, a quadratic in experience, the previous-period unemployment rate in the current state of residence, and an indicator for having made a move since the previous period. Here, I define a move as changing counties or states, that is, moving to a different local labor market. I estimate this linear probability model separately by previous employment status.

The results of these descriptive regressions are shown in Table 3. For employed workers, the mover dummy coefficient is -12 percentage points, indicating a large penalty for employed movers. For the non-employed, there is actually a slight gain to moving - non-employed movers are about 5 percentage points more likely to be employed than non-employed stayers. ${ }^{\mathrm{xv}}$ Finally, an increase in the state unemployment rate reduces the employment probability of the non-employed by more than it does the employed. In this sense, the employed are more insulated from local economic downturns than those who are not employed.

Although the above facts are illustrative, they are likely biased due to mismeasurement of the local labor market, endogeneity of migration, and unobserved worker heterogeneity. Additionally, the incentives to move faced by the employed and non-employed are myriad and 
require a more careful unpacking. In the next section, I introduce a structural model in which forward-looking individuals choose where to live and whether to supply labor. Individuals take into account that moving is costly and that employment is uncertain and is affected by local labor market conditions. I then estimate the model on the estimation subsample using restricted-access SIPP data that allows me to more precisely observe local labor markets. The model's inclusion of switching costs and search frictions allows me to examine the extent to which these phenomena might confer monopsony power to firms that have competitors in other labor markets, but not in their own labor market.

\section{A Model of Search Frictions, Labor Supply, and Migration}

I now introduce the model that I will estimate and use to quantify moving costs, labor market frictions, and to examine counterfactual scenarios that will shed light on workers' spatial responsiveness to changes in their local labor market.

\section{III.A Overview}

In each period, individuals choose whether or not to supply labor in one of 55 locations. The choice set is exhaustive in that in covers every possible location in the United States, and every possible labor market status. Search frictions are a key element of the model. That is, although an individual may control his labor supply decision, he cannot control his employment outcome. For example, a non-employed worker may exogenously receive a job offer or an employed worker may exogenously be laid off. Furthermore, these job offer and destruction rates are allowed to vary by location, migration status, and calendar time, thus capturing heterogeneity in local business cycles and spatial frictions in job search. Allowing individuals to choose to supply labor is essential to the model, because the employment probabilities are conditional on labor force participation. ${ }^{\text {xvi }}$ I specify the job search parameters in a reduced form, but the underlying search process relates to 
a Burdett and Mortensen (1998) approach where workers can move locations and enter or exit the labor force.

Individuals are forward-looking and in each period choose the alternative that maximizes their present discounted value of utility. Thus, individuals take into account local labor market conditions when choosing where to locate — in addition to amenities and earnings prospects, which have been traditionally modeled in the migration literature. ${ }^{x v i i}$ Individuals also understand that there are costs associated with changing locations or labor force status. These costs motivate individuals to be forward-looking when considering their decision in each period.

This model is the first to examine locational choice and labor supply in a dynamic setting with time-varying search frictions that are tied to local business cycles. It is also the first to examine how moving costs differ by employment status. I now present each feature of the model in more detail, beginning with the individual's dynamic optimization problem. Complete details of the model are included in Online Appendix Section A.1.

\section{III.B The individual's dynamic optimization problem}

In each period $t$, individual $i$ observes a vector of state variables $Z_{i t}$ and preference shocks $\varepsilon_{i j \ell t}$ and receives utility equal to $u_{i j \ell t}\left(Z_{i t}\right)+\varepsilon_{i j \ell t}$, according to a potential choice pair $(j, \ell)$ which respectively indexes labor force status and location. The individual sequentially chooses $d_{i t}$ to maximize the sum of his present discounted utility according to the following expression:

$$
\max _{d_{i t}} E\left[\sum_{t=0}^{T} \beta^{t} \sum_{j} \sum_{\ell}\left(u_{i j \ell t}\left(Z_{i t}\right)+\varepsilon_{i j \ell t}\right) 1\left\{d_{i t}=(j, \ell)\right\}\right]
$$

with discount factor $\beta$ and where $1\{\cdot\}$ is the indicator function. The individual observes the current-period vector of preference shocks $\boldsymbol{\varepsilon}_{i t}$ before making a decision, but does not observe 
future shocks and must take expectations accordingly. The individual also may not observe future values of the states $Z_{i t}$ and may have to integrate over those as well.

Under mild regularity conditions, Equation 1 follows Bellman's optimality principle. ${ }^{\text {viii }}$ The ex ante value function, just before $\boldsymbol{\varepsilon}_{i t}$ is revealed, is given below.

(2)

$$
V_{i t}\left(Z_{i t}\right)=E_{\varepsilon} \max _{j, \ell}\left\{u_{i j \ell t}\left(Z_{i t}\right)+\varepsilon_{i j \ell t}+\beta \int V_{i t+1}\left(Z_{i t+1}\right) d F\left(Z_{i t+1} \mid Z_{i t}\right)\right\}
$$

Equations 1 and 2 establish the mathematical framework through which individuals make forward-looking decisions. Specifically, individuals integrate over unknown future preference shock realizations $\varepsilon_{i j \ell t}$ using the value function. ${ }^{\text {xix }}$

\section{III.C Amenities, expected earnings, employment probabilities, and switching costs}

I now briefly discuss how the flow utility terms in Equation 2 are specified. The model incorporates unobserved heterogeneity by means of a finite mixture model, where individuals are divided into latent groups. Online Appendix Section A.1 contains complete details of every equation and parameter that enters the model. In all, the model has 1,012 parameters. ${ }^{\mathrm{xx}}$ Although the number of parameters appears to be large, there are multiple equations in the model, and the equations with continuous outcomes contain the majority of the parameters. I discuss these details further in Section IV.A.

\section{III.C.1 Amenities}

Because individuals choose among various locations, amenities are a key component of utility. I specify two types of amenities: local amenities on which all individuals' rankings are identical, and private amenities on which individual rankings may differ. Local amenities include attributes such as climate, crime, and geography. Private amenities include whether the location is in the state or Census division where the individual was born. Specifying private 
amenities in this way allows for individuals to have preferences for family proximity or other non-market local ties, which have been shown to be an important aspect of location choice (Koşar, Ransom, and van der Klaauw, Forthcoming).

\section{III.C.2 Expected log earnings}

Individuals also choose whether or not to supply labor. Naturally, earnings are a function of flow utility if a person becomes employed. However, as a simplifying assumption, I specify that the expected portion of the natural logarithm of earnings is what enters utility. ${ }^{x x i}$ I assume that expected earnings are composed of a location-time fixed effect, a quadratic function of experience, and a type dummy that represents productivity that is unobserved to the researcher but observed to the individual. Because earnings are a function of a location-time fixed effect, individuals must forecast their future evolution. They do so using an AR(1) process (with drift) specific to each labor market.

\section{III.C.3 Employment probabilities}

Employment probabilities also affect whether someone decides to supply labor. I specify the flow utility of labor force participation to be a weighted sum of the flow utility of being employed (which includes earnings) and the flow utility of being unemployed (which includes a job search cost), where the employment probabilities are the weights.

The employment probabilities follow a form similar to the descriptive linear probability models reported in Table 2: they depend on prior employment status, whether the person is a new move-in, the lagged unemployment rate of the location, and the same unobserved type that enters earnings. As with earnings, individuals must forecast how location-specific employment probabilities will evolve over time. They forecast the local unemployment rate according to an $\mathrm{AR}(1)$ process (with drift) specific to each location. 


\section{III.C.4 Switching costs}

An important component of the flow utility is switching costs. These are specified in two dimensions: switching locations (that is, moving costs) and switching labor force status. The moving cost includes a constant, a quadratic in distance, a quadratic in age, dummies for prior employment status, and the same unobserved type that enters the earnings and employment probabilities. Labor force switching costs include a constant, a quadratic in age, and the unobservedtype.

\section{Identification and Estimation}

This section informally discusses identification of the model and provides further details on the estimation procedure.

\section{IV.A Identification}

I now briefly discuss how the key parameters of the model are identified. These include the earnings and employment parameters, as well as the amenities and moving and switching costs, each of which comes from a separate equation of the model (Willis and Rosen, 1979). With sufficient variation in the outcome and covariates of each equation, the parameters are identified. The equation with the least amount of variation in the outcome (the multinomial choice equation) thus contains the fewest number of parameters. I provide more comprehensive details on identification in Online Appendix Section A.2.

As with any causal analysis using observational panel data, identification ultimately requires making assumptions. In my case, where the model is a system of non-linear equations, these include the following assumptions: $(i)$ person-specific unobservables follow a discrete distribution; (ii) there are valid exclusion restrictions to tell apart different equations in the model; (iii) individuals pre-commit to working when entering the labor force; and (iv) 
functional form assumptions that are standard in structural econometrics. ${ }^{x \mathrm{xi}}$

The unobserved type-which enters the earnings, employment probabilities, and moving and switching costs - is the way in which the model accounts for selection on unobservables. A crucial assumption for identification is that the person-specific unobservables are discretely distributed. Additionally, in a non-linear panel model such as the one used here, the unobservable type needs to be treated as a random effect for consistent estimation. This means that the unobserved type is necessarily uncorrelated with the time-invariant variables included in the model, but it can be correlated with the model's time-varying variables or with other characteristics observed in the data but left out of the model. As with other panel models, identification of this latent type relies on within-person serial correlation in the residuals of each equation. For example, workers with earnings that are persistently higher than their observables would predict are labeled as the "high type."

Another key to identification is exclusion restrictions for the flow utility. Identification of the coefficient on expected log earnings requires variation in expected log earnings that is not elsewhere present in the flow utility equation. I follow Arcidiacono et al. (2016) in specifying that work experience and calendar time dummies do not enter the flow utility except through expected log earnings. Likewise, the employment probabilities enter the flow utility, and identification of the disutility of unemployment is aided by excluding the local unemployment rate and work experience from the flow utility equation.

Finally, identification of the employment probability parameters also requires the assumption of pre-commitment to work.

\section{IV.B Estimation of earnings, employment, and utility parameters}

I estimate the parameters of the model using maximum likelihood and an iterative procedure 
know as the Expectation-Maximization (EM) algorithm. This is an algorithm that greatly simplifies the estimation of finite mixture models like the one I specify here. The key idea is that I can estimate each equation of the model separately, treating the latent type as given. I fully detail this estimation algorithm in Online Appendix Sections A.3.1 through A.3.3.

Under the simplification of the EM algorithm, estimation of the log earnings equation amounts to weighted OLS. The two employment probability equations - conditional on either employment or non-employment in the previous period—simplify to weighted binary logits. The labor market forecasting equations for the local earnings level and local unemployment rate are each a system of $55 \mathrm{AR}(1)$ equations that are estimated using equation-by-equation OLS.

Estimation of the flow utility parameters is much more involved than the other parameters in the model. This is because the value function in Equation 2 is a recursive object and I would need to solve it at each iteration of the maximum likelihood estimation algorithm. Rather than pursue this strategy—which would be computationally infeasible for my model—I break the recursion by using two separate simplification tools that are closely related: (i) conditional choice probabilities (CCPs; see Hotz and Miller, 1993); and (ii) finite dependence (see Arcidiacono and Miller, 2011, 2019). CCPs make use of a function mapping future value terms from the individual's dynamic programming problem into the probability of making a discrete choice. Finite dependence allows the researcher to formulate the recursive future value terms into a finite sequence of future payoffs. Together, the two strategies yield substantial computational savings by eliminating the need to solve the dynamic programming problem using backwards recursion.

Under the simplification of CCPs and finite dependence, estimation of the recursive flow 
utility parameters reduces to a multi-stage static problem, which can be estimated using a McFadden (1974) conditional logit model with an adjustment term that captures the future value associated with each alternative.

\section{Empirical Results}

This section discusses the main estimates of interest. I discuss estimates of employment probabilities, earnings, and unobserved types. I then use the estimates to compute implied moving costs and amenity values. The results show that labor market frictions are especially hindering to employed workers, who see on average a 20 percentage point lower likelihood of finding a job after a move. The results also show that moving costs are large, with an average net present value on the order of $-\$ 400,000$. Combined, these two factors inhibit worker flows across labor markets, thus granting market power to firms in sectors where workers have few within-location employment options.

\section{V.A Employment probabilities, earnings and unobserved types}

I begin by discussing the estimated employment probabilities and their evolution over the business cycle, as reported in Table 4 . This table lists the estimates of separate binary logits that predict the probability of being employed conditional on previous employment status. I present the estimates for two different specifications: no unobserved heterogeneity, and two unobserved types. ${ }^{\text {xxiv }}$ The results confirm the findings in Section II.B: The employed are more shielded from local economic downturns, but employed movers face a steep employment penalty ( $\approx 20$ percentage points) in the new location. ${ }^{\mathrm{xxv}}$ This employment penalty for employed movers relative to non-employed movers indicates that search frictions are a hindrance for the employed. An additional finding from the structural model is that there is comparative advantage in job-finding based on employment status. That is, type 1 workers are much more 
likely than type 2 workers to stay employed, but are much less likely to be hired from nonemployment.

Table 5 presents estimates of the structural log earnings equation. The main takeaway is that type 1 workers are more productive when employed, as they earn a wage premium of $67 \log$ points over type 2 workers.

As discussed in Section IV.A, unobserved types play a crucial role in accounting for unobservable characteristics and increasing the plausibility of the structural model. By virtue of it being a random effect, the unobserved type is uncorrelated with the model's timeinvariant state variables. However, it may be correlated with time-varying state variables (such as work experience) or other information in the SIPP that is not included in the model, such as industry, occupation, marital status, home ownership status, or years of completed education.

Without the ability to include measurements of cognitive or non-cognitive skills (because the SIPP does not collect information on these), the interpretation of the unobserved type must come from the equations where it enters in the model. The earnings equation indicates a substantial earnings premium for type 1 workers, and the employment probability equations indicate that type 1 workers are more likely to remain employed. Coupled with the flow utility parameter estimates in Table 6 (which indicate that type 1 workers are more mobile), this suggests that type 1 workers possess higher levels of cognitive and/or non-cognitive skills than type 2 workers. ${ }^{\text {xxvi }}$ The fact that type 1 workers have a comparative advantage in remaining employed could also reflect the variety of industries or occupations they are in. If type 1 workers tend to work in industries or occupations with connections, being employed would open doors to other offers, but it may be difficult to get an offer if unemployed.

V.B Moving costs and amenity values 
Table 6 presents the flow utility parameter estimates, which can be used to compute moving costs and amenity values. The highlight of this table is that both employed and type 1 workers have lower moving costs. This is because a positive coefficient indicates a cost that is smaller in magnitude, because the fixed cost of moving is a large and negative number. It is somewhat surprising that the employed have lower moving costs, given that Figure 1 showed that these workers are less mobile than the non-employed. This apparent contradiction is resolved by the findings in Section V.A that showed that the employed face a greater degree of search frictions when moving. Workers' movement may be inhibited either by search frictions or moving costs. My results highlight the asymmetry in these two inhibitors based on whether the worker is currentlyemployed.

The finding of lower moving costs among type 1 workers is consistent with other studies that have found that cognitive and non-cognitive abilities are correlated with migration — that is, those who are more productive in the labor market also have lower moving costs (Bütikofer and Peri, Forthcoming). This is because type 1 workers have much higher earnings and hence are likely to have greater endowments of abilities, although this claim is impossible to evaluate in the SIPP due to a lack of measurements of abilities. In other aspects, the flow utility parameter estimates conform to economic theory and the previous literature. ${ }^{x x i i}$

Using the parameter estimates in Table 6, I can calculate the monetary value of moving costs and amenity values. The expected earnings parameter can be used to convert utility to money and thus to express the structural parameter estimates in monetary units. I provide complete details in Online Appendix Section A.4 on how this is done. It is also important to note that these moving cost estimates represent the moving costs faced by the average individual, not the marginal individual (that is, not the person who is just indifferent between 
staying and moving). In Table 7, I present sample moving costs by previous employment status and unobserved type in two forms: net present value and percentage equivalent of per-period earnings. The latter form can be used to compare the results with other papers in the dynamic migration literature, while the former can be used to compare the results with other papers that have calculated moving costs in terms of willingness to pay.

In terms of net present value, the fixed cost of moving ranges from $-\$ 105,000$ for an employed type 1 person to $-\$ 140,000$ for an unemployed type 2 person. The moving cost evaluated at the average person's characteristics and for the average move path ranges from $-\$ 394,000$ to $\$ 459,000$. These figures are similar in magnitude to those reported in Kennan and Walker (2011), Bishop (2012), and Bartik (2018). ${ }^{\mathrm{x} v i i i}$ Importantly, the monetary value of the moving cost reflects psychological costs of moving (for example acclimating to a new location or leaving behind friends and family) in addition to monetary costs (for example costs to procure a moving truck or close on a mortgage). In terms of percentage of flow earnings, the fixed cost of moving is between $-30 \%$ and $-40 \%$, meaning that a person would not be willing to move unless he received at least a $30 \%-40 \%$ increase in earnings in perpetuity. For the average move, this number is above $100 \%$. Koşar, Ransom, and van der Klaauw (Forthcoming) find similar magnitudes, although their model is static.

In addition to moving costs, I compute amenity values and find them to be economically significant, but not nearly as large as moving costs. The results indicate that a one-standarddeviation increase in local amenities has a net present value of about $\$ 23,000$, while moving from the bottom to the top of the amenity distribution would be worth over $\$ 91,000$. Preferences for birth state proximity are in between these two values at about $\$ 57,000$. This value partly explains why such a high fraction of individuals in the data are observed to be living in their birth 
state.

One might wonder why the estimated moving costs are so large. The primary explanation is that there is a weak relationship between expected earnings and observed moves. Salary is just one of a list of many potential reasons for moving, and although the elasticity of earnings is positive (as predicted by economic theory), the moves observed in the data on average are not strongly related to increases in expected earnings. Additionally, the moving cost represents the cost faced to the average individual if he were forced to move to an arbitrary location in an arbitrary time period, and the current model assumes that individuals consider moving to each location in every period. ${ }^{\text {xix }}$ This assumption is likely unrealistic, since moving is only salient when certain events in life trigger a move (for example, pursuit of education, change of job, change of household structure, health of family members, etc.). For recent work that incorporates this feature, see Schluter and Wilemme (2018) and Schmutz and Sidibé (2019). Even if my estimated moving costs are overstated, it is still the case that preferences for non-market amenities and labor market frictions reduce mobility across labor markets.

\section{Model Fit and Counterfactual Simulations}

In this section, I verify that the structural model fits the data well, and then discuss the results obtained from counterfactual simulations of the model. The results of these simulations illustrate the extent to which workers remain in their labor market in response to a variety of shocks, and hence the extent to which monopsony power may generally operate. I also calibrate a model of firm choice to illustrate the effect of switching costs on a firm's labor supply elasticity.

\section{VI.1 Model Fit}

It is crucial to check the fit of the model to ensure that the model-based counterfactuals are 
credible. In Tables 8 and 9, I show migration probabilities and employment transitions in the model and in the data. Panel (a) of Table 8 shows how migration varies by previous employment status and calendar time. The model matches these differences well over adjacent time periods. Migration probabilities over previous employment crossed with age and distance are shown in panels (b) and (c) of this table. The model and data also match up well along these dimensions.

Table 9 compares employment transitions across successive time periods in the data and model, conditional on migrating or staying. Panel (a) compares employment transition rates conditional on migrating. These match up very closely with the exception of remaining out of the labor force for non-participants. This is likely due to the fact that, in the data, there are relatively few nonparticipant movers who remained out of the labor force after moving. Panel (b) compares these transitions conditional on staying in a location. Again, the data and model match up well.

I present the model fit for adjacent time periods - and not longer horizons-because the counterfactual simulations also only cover adjacent time periods. The reason for only considering counterfactuals of this sort stems from how the model is estimated. The CCP method explained in Section IV.B eliminates the need to solve the value function. It also allows the future value terms to not be driven by assumptions about how expectations are formed far out into the future. The downside is that these future value terms are not valid in counterfactual scenarios that go beyond $t+1$. Counterfactuals covering a longer time period would require fully solving the value function, which in this case is computationally infeasible.

\section{VI.2 Counterfactual Simulations}

Now that I have established that the model fits the data well, I discuss counterfactual simulations of the model that further illustrate the importance of moving costs and search frictions. To get a 
sense of the degree to which workers would migrate, I simulate the migration response to five different counterfactual policies of 25 -year-olds who were not born in the location. I examine heterogeneity in migratory response by separately analyzing each unobserved worker type living in two artificial cities - one with very desirable amenities, and the other with very undesirableamenities. ${ }^{\mathrm{xxx}}$ The five policies I examine are the following: two separate shocks to local expected earnings; two separate shocks to the local unemployment rate; and a moving subsidy worth $10 \%$ of the fixed cost of moving $(\approx \$ 10,000$ in net present value). For earnings and unemployment, I respectively consider a purely localized shock and a shock that is spatially correlated (but originating in the current location). ${ }^{\mathrm{xxx}}$ For reasons discussed above, I only examine temporary counterfactual policies. That is, each policy is in effect for only one calendar year. However, because of the autocorrelated structure of some components of the model, the effect of each counterfactual policy may not be temporary.

I focus my discussion on the impact of the policies on out-migration of young workers who were not born in the impacted location, because these are the workers who are most responsive to such policies. As such, the migration responses I document are upper bounds on the population-level average response: repeating the exercise for older workers, or for workers born in the origin location would result in much lower responses because these other groups are more tied to their current location.

The results of the simulations are reported in Figure 2, which show the change in outmigration probability for each policy. Baseline predicted out-migration rates for each city and employment group are listed just above the horizontal axis. ${ }^{\text {xxxii }}$ The first four bars in each panel report the simulated response to independent and correlated adverse shocks to earnings and employment in each location, while the last bar reports the moving subsidy response. ${ }^{\text {xxxii }}$ 
The key result from Figure 2 is the difference in behavior between employed and unemployed workers when faced with unemployment shocks (the third and fourth bars). ${ }^{\text {xxiv }}$ This difference stems from the difference in employment probabilities that these groups face when moving, and highlights the importance of labor market frictions in explaining worker mobility across labor markets. Employed workers are more likely to stay in their current location when faced with either a localized or correlated shock, whereas the opposite is true for unemployed workers. ${ }^{\mathrm{xxx}}$.

In addition to the importance of labor market frictions, Figure 2 also shows the role of moving costs in explaining migration behavior. The last bar of each panel of Figure 2 reports the simulated impact of a moving cost subsidy of approximately $\$ 10,000(10 \%$ of the fixed cost of moving for employed type 1 workers). For all cities and employment statuses, out-migration rates increase, but are relatively modest. The increase in migration probability is on the order of $33 \%$ (or an increase of no more than 5 percentage points off a base of $15 \%$ ). ${ }^{\mathrm{xxvi}}$

\section{VI.3 Monopsony and Firm Switching Costs}

The results of these counterfactual simulations illustrate the importance of labor market frictions and moving costs in inhibiting the movement of workers across labor markets, even if workers are offered a sizable moving subsidy. However, they do not directly lead to an estimate of employer market power, such as a firm-level labor supply elasticity. To show how labor market frictions lead to monopsony power, I calibrate a model of firm choice that bears resemblance to my empirical model. The model combines elements of the so-called new classical monopsony literature (Card et al., 2018; Lamadon, Mogstad, and Setzler, 2019; Azar, Berry, and Marinescu, 2019; Manning, Forthcoming) with the so-called modern monopsony literature (Manning, 2003; Hirsch et al., 2019; Manning, Forthcoming). In "new classical" 
models, workers have idiosyncratic tastes for wage and non-wage amenities offered by firms, while in "modern" models, workers face frictions in changing jobs. Both preferences for nonwage amenities and frictions in changing jobs grant market power to employers.

I leave the complete details of the calibrated model to Online Appendix A.9. Briefly summarizing, the model has workers choosing a firm at which to work, with firms differentiated by wages and non-wage amenities. Firms are located in geographic markets, where there are 35 markets each with 20 firms. Workers have idiosyncratic preferences for a given firm, and workers also face costs to switching firms. I focus on switching costs because search frictions can be characterized as a type of switching cost. In the model, it is more costly for workers to switch to a firm in a different geographic market. The model allows me to calculate the labor supply elasticity of each firm, given calibrated parameter values. I report in Online Appendix Table A13 the implied average labor supply elasticity for an array of parameter values.

My main findings are that the firm labor supply elasticity ranges from 0.4 to 3 , depending on how responsive workers are to outside wages and on how costly it is for workers to change employers. Using the estimate of $\hat{\gamma_{0}}=1$ as reported in Table 6, this would imply that firms' labor supply elasticity ranges from 0.4 to 1 over a reasonable range of switching costs. These numbers correspond to a wage markdown of $50 \%-72 \%$. Under the more reasonable assumption that workers are more responsive to outside wages within their location (for example $\gamma_{0}=3$ ), the labor supply elasticity ranges from 1 to 3 . This implies a wage markdown of $25 \%-50 \%$, which much more in line with other papers from the monopsony literature (Manning, 2011).

\section{Conclusion}

Search frictions and switching costs are thought to grant monopsony power to incumbent 
employers because they reduce workers' outside options. This paper has studied the extent to which labor market frictions and moving costs inhibit migration of American workers who are not college graduates. To quantify these two determinants of employer market power, I have developed and tractably estimated a rich dynamic structural model that incorporates search frictions.

I find that moving costs are substantial and that employed movers see a steep reduction in the job-finding rate after a move. Because migration decisions observed in the data are only loosely related to cross-location earnings differences, this implies that moving costs must be large. That is, workers have sizable preferences for market and non-market amenities which weaken the role of earnings in the migration decision. Labor market frictions are also important. Even though the employed have lower moving costs, counterfactual simulations of the model show that they are less likely to move in response to a shock to the local unemployment rate. This is because they face a steep decline in employment likelihood if they move locations.

I use the model to simulate the effect of a moving subsidy offered to both employed and unemployed workers. Owing to large moving costs, the subsidy has low take-up rates $(\approx 3 \%-$ $5 \%$ ). The unemployed are more likely to take the subsidy, because they have roughly the same likelihood of employment whether or not they move.

Taking my model of location choice and extrapolating it to a model of firm choice illustrates that firm switching costs grant a substantial amount of market power to firms. In the absence of switching costs, a worker's wage markdown would fall by as much as one-half. 


\section{References}

Amior, Michael and Alan Manning. 2018. "The Persistence of Local Joblessness." American Economic Review 108 (7):1942-1970.

Arcidiacono, Peter, Esteban Aucejo, Arnaud Maurel, and Tyler Ransom. 2016. "College Attrition and the Dynamics of Information Revelation." Working Paper 22325, National Bureau of Economic Research.

Arcidiacono, Peter and Robert A. Miller. 2011. "Conditional Choice Probability Estimation of Dynamic Discrete Choice Models with Unobserved Heterogeneity." Econometrica 79 (6): $1823-1867$.

.2019. "Nonstationary Dynamic Models with Finite Dependence." Quantitative Economics 10 (3):853-890.

Azar, José, Steven Berry, and Ioana Marinescu. 2019. "Estimating Labor Market Power." Working paper, IESE Business School.

Balgova, Maria. 2018. "Why Don't Less Educated Workers Move? The Role of Job Search in Migration Decisions." Working paper, Oxford University.

Bartik, Alexander W. 2018. "Moving Costs and Worker Adjustment to Changes in Labor Demand: Evidence from Longitudinal Census Data." Working paper, University of Illinois at Urbana-Champaign.

Baum-Snow, Nathaniel and Ronni Pavan. 2012. "Understanding the City Size Wage Gap." Review of Economic Studies 79 (1):88-127.

Bayer, Patrick, Nathaniel Keohane, and Christopher Timmins. 2009. "Migration and Hedonic Valuation: The Case of Air quality." Journal of Environmental Economics and Management $58(1): 1-14$.

Bhaskar, V., Alan Manning, and Ted To. 2002. "Oligopsony and Monopsonistic Competition in Labor Markets." Journal of Economic Perspectives 16 (2):155-174.

Bhaskar, V. and Ted To. 1999. "Minimum Wages for Ronald McDonald Monopsonies: A Theory of Monopsonistic Competition." Economic Journal 109 (455):190-203.

Bhaskar, V.and Ted To. 2003. "Oligopsony and the Distribution of Wages." European Economic Review 47 (2):371-399.

Bishop, Kelly. 2012. "A Dynamic Model of Location Choice and Hedonic Valuation." Working paper, Washington University in St. Louis.

Blanchard, Olivier and Lawrence F. Katz. 1992. "Regional Evolutions." Brookings Papers on Economic Activity 1992 (1):1-75.

Burdett, Kenneth and Dale T. Mortensen. 1998. "Wage Differentials, Employer Size, and Unemployment." International Economic Review 39 (2):257-273. 
Bütikofer, Aline and Giovanni Peri. Forthcoming. "How Cognitive Ability and Personality Traits Affect Geographic Mobility." Journal of Labor Economics .

Caliendo, Marco, Steffen Künn, and Robert Mahlstedt. 2017. "Mobility Assistance Programmes for Unemployed Workers, Job Search Behaviour and Labour Market Outcomes." Discussion Paper 11169, IZA.

Card, David, Ana Rute Cardoso, Joerg Heining, and Patrick Kline. 2018. "Firms and Labor Market Inequality: Evidence and Some Theory." Journal of Labor Economics 36 (S1):S13-S70.

Coate, Patrick. 2013. "Parental Influence on Labor Market Outcomes and Location Decisions of Young Workers." Working paper, Duke Univeristy.

Coate, Patrick and Kyle Mangum. 2019. "Fast Locations and Slowing Labor Mobility." Working Paper 19-49, Federal Reserve Bank of Philadelphia.

Diamond, Rebecca. 2016. "The Determinants and Welfare Implications of US Workers' Diverging Location Choices by Skill: 1980-2000.” American Economic Review 106 (3):479-524.

Foote, Andrew, Michel Grosz, and Ann Stevens. 2019. "Locate Your Nearest Exit: Mass Layoffs and Local Labor Market Response." ILR Review 72 (1):101-126.

Fox, Jeremy T. 2010. "Estimating the Employer Switching Costs and Wage Responses of ForwardLooking Engineers." Journal of Labor Economics 28 (2):357-412.

Gardner, John and Joshua R. Hendrickson. 2018. "If I Leave Here Tomorrow: An Option View of Migration When Labor Market Quality Declines." Southern Economic Journal 84 (3):786-814.

Glaeser, Edward and David Maré. 2001. "Cities and Skills." Journal of Labor Economics 19 (2):316-342.

Gould, Eric. 2007. "Cities, Workers and Wages: A Structural Analysis of the Urban Wage Premium." Review of Economic Studies 74 (2):477-506.

Handwerker, Elizabeth Weber and Matthew Dey. 2019. "Variation in the Impact of Explicit Oligopsony by Occupation." Working paper, Bureau of Labor Statistics.

Hirsch, Boris, Elke J. Jahn, Alan Manning, and Michael Oberfichtner. 2019. Discussion Paper 1608, Center for Economic Performance.

Hotelling, Harold. 1929. "Stability in Competition.” Economic Journal 39 (153):41-57.

Hotz, V. Joseph and Robert A. Miller. 1993. "Conditional Choice Probabilities and the Estimation of Dynamic Models." Review of Economic Studies 60 (3):497-529.

H.R. 2755. 2015. “American Worker Mobility Act of 2015.” 114th Congress.

Huttunen, Kristiina, Jarle Møen, and Kjell G. Salvanes. 2018. “Job Loss and Regional Mobility.” Journal of Labor Economics 36 (2):479-509. 
Karahan, Fatih and Serena Rhee. 2017. "Population Aging, Migration Spillovers, and the Decline in Interstate Migration." Staff Report 699, Federal Reserve Bank of New York. URL https:// www.newyorkfed.org/medialibrary/media/research/staff_reports/sr699.pdf.

Kennan, John and James R. Walker. 2011. "The Effect of Expected Income on Individual Migration Decisions.” Econometrica 79(1):211-251.

Koşar, Gizem, Tyler Ransom, and Wilbert van der Klaauw. Forthcoming. "Understanding Migration Aversion Using Elicited Counterfactual Choice Probabilities." Journal of Econometrics.

Lamadon, Thibaut, Magne Mogstad, and Bradley Setzler. 2019. "Imperfect Competition, Compensating Differentials and Rent Sharing in the U.S. Labor Market." Working Paper 25954, National Bureau of Economic Research.

Mangum, Kyle. 2015. “Cities and Labor Market Dynamics.” Working Paper 2015-2-3, Georgia State University.

Manning, Alan. 2003. Monopsony in Motion: Imperfect Competition in Labor Markets. Princeton University Press.

. 2011. "Imperfect Competition in the Labor Market." In Handbook of Labor

Economics, vol. 4B, edited by Orley Ashenfelter and David Card. Amsterdam: Elsevier, 9731041.

. Forthcoming. "Monopsony in Labor Markets: A Review.” ILR Review .

Marinescu, Ioana and Roland Rathelot. 2018. "Mismatch Unemployment and the Geography of Job Search.” American Economic Journal: Macroeconomics 10 (3):42-70.

McFadden, Daniel. 1974. "Conditional Logit Analysis of Qualitative Choice Behavior.” In Frontiers in Econometrics, edited by Paul Zarembka. Academic Press, New York, 105-142.

Molloy, Raven S. and Abigail Wozniak. 2011. "Labor Reallocation over the Business Cycle: New Evidence from Internal Migration.” Journal of Labor Economics 29 (4):697-739.

Monras, Joan. 2018. “Economic Shocks and Internal Migration.” Discussion Paper 12977, Centre for Economic Policy Research.

Moretti, Enrico. 2012. The New Geography of Jobs. New York: Houghton Mifflin Harcourt.

Morten, Melanie and Jaqueline Oliveira. 2016. "Paving the Way to Development: Costly Migration and Labor Market Integration.” Working Paper 22158, National Bureau of Economic Research.

Notowidigdo, Matthew J. 2020. "The Incidence of Local Labor Demand Shocks." Journal of Labor Economics 38 (3): 687-725.

Ransom, MichaelR. 1993. "Seniority and Monopsony in the AcademicLabor Market." American Economic Review 83 (1):221-233. 
Salop, Steven C. 1979. "Monopolistic Competition with Outside Goods." Bell Journal of Economics 10 (1):141-156.

Sastry, Narayan and Jesse Gregory. 2014. "The Location of Displaced New Orleans Residents in the Year After Hurricane Katrina.” Demography 51 (3):753-775.

Schlottmann, Alan M. and Henry W. Herzog, Jr. 1981. "Employment Status and the Decision to Migrate." Review of Economics and Statistics 63(4):590-598.

Schluter, Christian and Guillaume Wilemme. 2018. "A Dynamic Empirical Model of Frictional Spatial Job Search.” Working paper, Aix-Marseille University.

Schmutz, Benoît and Modibo Sidibé. 2019. "Frictional Labour Mobility." Review of Economic Studies 86 (4):1779-1826.

Shenoy, Ashish. 2016. "Migration Decisions and Persistent Earnings Differentials: Evidence from Thailand.” Working paper, University of California atDavis.

Staiger, Douglas O., Joanne Spetz, and Ciaran S. Phibbs. 2010. "Is There Monopsony in the Labor Market? Evidence from a Natural Experiment.” Journal of Labor Economics 28 (2):211-236.

Topel, Robert H. 1986. “Local Labor Markets.” Journal of Political Economy 94 (3):S111-S143.

Willis, Robert J. and Sherwin Rosen. 1979. "Education and Self-Selection." Journal of Political Economy 87 (5, Part 2):S7-S36.

Wilson, Riley. Forthcoming. "Moving to Jobs: The Role of Information in Migration Decisions." Journal of Labor Economics.

. Forthcoming. "Moving to Economic Opportunity: The Migration Response to the Fracking Boom.” Journal of Human Resources .

Winters, John V. 2009. "Wages and Prices: Are Workers Fully Compensated for Cost of Living Differences?” Regional Science and Urban Economics 39 (5):632-643.

Yagan, Danny. 2014. "Moving to Opportunity? Migratory Insurance over the Great Recession." Working paper, UC Berkeley.

Zabel, Jeffrey E. 1998. "An Analysis of Attrition in the Panel Study of Income Dynamics and the Survey of Income and Program Participation with an Application to a Model of Labor Market Behavior." Journal of Human Resources 33 (2):479-506. 


\section{Figures and Tables}

Table 1: Descriptive statistics of the estimation subsample of the SIPP, 2004-2013

\begin{tabular}{lcc}
\hline Variable & Mean & Std Dev \\
\hline Log monthly earnings (2000 dollars) $^{\mathrm{a}}$ & 7.96 & 0.52 \\
Work experience (years) & 22.60 & 9.49 \\
Age (years) & 42.29 & 9.76 \\
Lives in location in birth state & 0.74 & 0.44 \\
Lives in location in birth Census division & 0.75 & 0.43 \\
\hline Number of persons & \multicolumn{2}{c}{16,648} \\
Number of observations & \multicolumn{2}{c}{50,415} \\
\hline
\end{tabular}

Notes: For complete sample selection rules, see Online Appendix Table A1.

a Conditional on being employed full-time with monthly earnings between $\$ 400$ and $\$ 22,000$. This variable has 29,238 person-year observations. The earnings variable is spatially deflated to account for differences in cost of living according to the procedure outlined in Online Appendix A.7 
Table 2: Migration in the SIPP, 2004-2013

\begin{tabular}{lc}
\hline Number of persons (age 18-55) & 16,648 \\
\hline Movers & 568 \\
Movers (\%) & 3.41 \\
Moves & 653 \\
Moves per mover & 1.15 \\
Repeat moves (\% of all moves) & 13.38 \\
Return moves (\% of all moves) & 8.98 \\
\hline
\end{tabular}

Note: Moves are defined as changing locations as specified in the model. 
Table 3: Linear probability models of employment, by lagged employment status

\begin{tabular}{|c|c|c|c|c|}
\hline \multirow[b]{2}{*}{ Variable } & \multicolumn{2}{|c|}{ Prev. employed } & \multicolumn{2}{|c|}{ Prev. non-employed } \\
\hline & Coeff & Std Err & Coeff & Std Err \\
\hline Constant & $0.7243 * * *$ & 0.0071 & $0.1976^{* * *}$ & 0.0059 \\
\hline Experience & $0.0123 * * *$ & 0.0005 & $0.0077^{* * *}$ & 0.0004 \\
\hline Experience $^{2} / 100$ & $-0.0200 * * *$ & 0.0012 & $-0.0142 * * *$ & 0.0011 \\
\hline Lagged state unempl. Rate & $-0.0038 * * *$ & 0.0006 & $-0.0060 * * *$ & 0.0006 \\
\hline Mover dummy & $-0.1219 * * *$ & 0.0080 & $0.0468 * * *$ & 0.0076 \\
\hline $\begin{array}{l}\text { Race } \times \text { gender dummies } \\
\text { Observations }\end{array}$ & 83 & & $\begin{array}{c}\checkmark \\
78057\end{array}$ & \\
\hline
\end{tabular}

Notes: Dependent variable is an indicator for being employed full-time in the current period. Sample includes all non-college graduates aged 18-55 in the 2004 and 2008 panels of the public-use SIPP who have completed their schooling. ${ }^{* * *} \mathrm{p}<0.01 ;{ }^{* *} \mathrm{p}<0.05 ;{ }^{*} \mathrm{p}<0.10$. 
Table 4: Structural employment probability equation estimates

\begin{tabular}{|c|c|c|c|c|c|c|c|c|}
\hline \multirow[b]{3}{*}{ Variable } & \multicolumn{4}{|c|}{1 type } & \multicolumn{4}{|c|}{2 types } \\
\hline & \multicolumn{2}{|c|}{ Prev. employed } & \multicolumn{2}{|c|}{ Prev. non-employed } & \multicolumn{2}{|c|}{ Prev. employed } & \multicolumn{2}{|c|}{ Prev. non-employed } \\
\hline & Coeff & Std Err & Coeff & Std Err & Coeff & Std Err & Coeff & Std Err \\
\hline Constant & $1.3056^{* * *}$ & 0.2220 & 0.2566 & 0.2237 & $0.9812 * * *$ & 0.2241 & $0.5035^{* * *}$ & 0.2264 \\
\hline Experience & $0.0858 * * *$ & 0.0091 & $0.0359 * * *$ & 0.0086 & $0.0847 * * *$ & 0.0092 & $0.0366^{* * *}$ & 0.0087 \\
\hline Experience $^{2} / 100$ & $-0.1228 * * *$ & 0.0208 & -0.0285 & 0.0219 & $-0.1224 * * *$ & 0.0211 & -0.0310 & 0.0221 \\
\hline Lagged local unempl. rate & $-0.0314 * * *$ & 0.0104 & $-0.0922 * * *$ & 0.0110 & $-0.0342 * * *$ & 0.0105 & $-0.0937 * * *$ & 0.0111 \\
\hline Mover dummy & $-0.9257 * * *$ & 0.1280 & 0.1929 & 0.1557 & $-1.0483 * * *$ & 0.1300 & 0.2359 & 0.1572 \\
\hline Unobserved type 1 & & & & & $0.7958 * * *$ & 0.0400 & $-0.5751 * * *$ & 0.0429 \\
\hline Location fixed effects & $\checkmark$ & & $\checkmark$ & & $\checkmark$ & & $\checkmark$ & \\
\hline Observations & 30,898 & & 9,949 & & 30,898 & & 9,949 & \\
\hline Persons & 12,013 & & 6,087 & & 12,013 & & 6,087 & \\
\hline
\end{tabular}

Notes: Reported numbers are coefficients from logit regressions conditional on previous employment status. ${ }^{* *} \mathrm{p}<0.01 ;{ }^{*} \mathrm{p}<0.05 ;{ }^{*} \mathrm{p}<0.10$. 
Table 5: Structural earnings equation estimates

\begin{tabular}{lccccc}
\hline & \multicolumn{2}{c}{1 type } & & \multicolumn{2}{c}{2 types } \\
\cline { 2 - 3 } \cline { 5 - 6 } Parameter & Coeff & Std Err & & Coeff & Std Err \\
\hline Constant & $7.5708^{* * *}$ & 0.0673 & & $7.2074 * * *$ & 0.0470 \\
Experience & $0.0432^{* * *}$ & 0.0015 & & $0.0411^{* * *}$ & 0.0010 \\
Experience $^{2} / 100$ & $-0.0595^{* * *}$ & 0.0033 & & $-0.0575^{* * *}$ & 0.0023 \\
Unobserved type 1 & & & $0.6773 * * *$ & 0.0039 \\
\hline Location-time fixed effects & $\checkmark$ & & \multicolumn{2}{c}{$\checkmark$} \\
Persons & 11,404 & & 11,404 \\
Observations & 29,238 & & 29,238 \\
\hline
\end{tabular}

Notes: Reported numbers are coefficients from an OLS log earnings regression conditional on full-time employment and observing earnings. See footnote (a) of Table 1 for complete details on this subsample. ${ }^{* * *} \mathrm{p}<0.01 ;{ }^{* *} \mathrm{p}<0.05 ;{ }^{*} \mathrm{p}<0.10$ 
Table 6: Structural choice equation estimates

\begin{tabular}{|c|c|c|c|c|c|}
\hline \multirow[b]{2}{*}{ Parameter } & \multirow[b]{2}{*}{ Symbol } & \multicolumn{2}{|c|}{1 type } & \multicolumn{2}{|c|}{2 types } \\
\hline & & Coeff & Std Err & Coeff & Std Err \\
\hline \multicolumn{6}{|l|}{ Job \& location preferences } \\
\hline Expected log earnings & $\left(\gamma_{0}\right)$ & $0.916 * *$ & 0.397 & $1.001 * *$ & 0.412 \\
\hline Home production benefit & $\left(\gamma_{1}\right)$ & -0.902 & 3.477 & $11.333 * * *$ & 3.453 \\
\hline Search cost & $\left(\gamma_{2}\right)$ & $-1.195 * * *$ & 0.069 & $-1.008 * * *$ & 0.070 \\
\hline Birth state bonus & $\left(\gamma_{3}\right)$ & $0.207 * * *$ & 0.072 & $0.210 * * *$ & 0.072 \\
\hline Birth division bonus & $\left(\gamma_{4}\right)$ & -0.002 & 0.073 & -0.003 & 0.073 \\
\hline \multicolumn{6}{|l|}{ Switching costs } \\
\hline Fixed cost & $\left(\theta_{12}-\theta_{8}\right)$ & $0.335 * *$ & 0.127 & $0.910 * * *$ & 0.126 \\
\hline Age & $\left(\theta_{13}-\theta_{9}\right)$ & $-0.095 * * *$ & 0.006 & $-0.106 * * *$ & 0.006 \\
\hline $\mathrm{Age}^{2} / 100$ & $\left(\theta_{14}-\theta_{10}\right)$ & $0.109 * * *$ & 0.008 & $0.121 * * *$ & 0.008 \\
\hline Unobserved type 1 & $\left(\theta_{15}-\theta_{11}\right)$ & & & $-0.746 * * *$ & 0.019 \\
\hline \multicolumn{6}{|l|}{ Moving costs } \\
\hline Fixed cost & $\left(\theta_{0}\right)$ & $-3.148 * * *$ & 0.361 & $-3.165 * * *$ & 0.362 \\
\hline Distance (1000 miles) & $\left(\theta_{1}\right)$ & $-2.063 * * *$ & 0.078 & $-2.066 * * *$ & 0.078 \\
\hline Distance $^{2}$ & $\left(\theta_{2}\right)$ & $0.369 * * *$ & 0.025 & $0.369 * * *$ & 0.025 \\
\hline Age & $\left(\theta_{3}\right)$ & $-0.094 * * *$ & 0.018 & $-0.101 * * *$ & 0.018 \\
\hline $\mathrm{Age}^{2} / 100$ & $\left(\theta_{4}\right)$ & $0.056 * *$ & 0.023 & $0.063 * * *$ & 0.023 \\
\hline Employed $_{t-1}$ & $\left(\theta_{5}\right)$ & $0.197 *$ & 0.110 & $0.252 * *$ & 0.110 \\
\hline Unemployed $_{t-1}$ & $\left(\theta_{6}\right)$ & $-0.230 *$ & 0.128 & $-0.239 *$ & 0.129 \\
\hline Unobserved type 1 & $\left(\theta_{7}\right)$ & & & $0.256 * * *$ & 0.045 \\
\hline $\operatorname{Pr}($ type $=1)$ & $\left(\bar{\pi}_{r}\right)$ & \multicolumn{2}{|c|}{$\mathrm{N} / \mathrm{A}$} & \multicolumn{2}{|c|}{0.4926} \\
\hline Observations & & \multicolumn{2}{|c|}{50,415} & \multicolumn{2}{|c|}{50,415} \\
\hline Persons & & \multicolumn{2}{|c|}{16,648} & \multicolumn{2}{|c|}{16,648} \\
\hline Discount factor & $(\beta)$ & \multicolumn{2}{|c|}{0.9} & \multicolumn{2}{|l|}{0.9} \\
\hline
\end{tabular}

Notes: Reported numbers are flow utility parameter estimates from the dynamic choice model detailed in Online Appendix Section A.1. Estimates of location-specific amenities (the $\alpha_{\ell}$ 's) are not reported due to Census Bureau rules regarding disclosure risk. ${ }^{* * *} \mathrm{p}<0.01 ; * * \mathrm{p}<0.05 ; * \mathrm{p}<0.10$ 
Table 7: Sample moving costs and amenity values in net present value and percentage of flow earnings)

\begin{tabular}{|c|c|c|c|c|}
\hline \multirow[b]{3}{*}{ Utility component } & \multicolumn{4}{|c|}{ Monetary value } \\
\hline & \multicolumn{2}{|c|}{ Type 1} & \multicolumn{2}{|c|}{ Type 2} \\
\hline & Employed & Unemployed & Employed & Unemployed \\
\hline \multicolumn{5}{|l|}{ Panel A: Net Present Value (US\$) } \\
\hline \multicolumn{5}{|l|}{ Moving costs } \\
\hline Fixed cost of moving & $-105,095$ & $-127,749$ & $-116,777$ & $-140,023$ \\
\hline Average mover, 500-mile move & $-394,446$ & $-436,458$ & $-416,095$ & $-459,270$ \\
\hline $\begin{array}{l}\text { Average mover, New York to Los } \\
\text { Angeles }\end{array}$ & $-570,671$ & $-622,158$ & $-597,202$ & $-650,115$ \\
\hline $\begin{array}{l}\text { Young mover, New York to Los } \\
\text { Angeles }\end{array}$ & $-312,595$ & $-342,163$ & $-327,841$ & $-358,186$ \\
\hline \multicolumn{5}{|l|}{ Amenities } \\
\hline Std. Dev. of local amenities & \multicolumn{4}{|c|}{23,356} \\
\hline Range of local amenities & \multicolumn{4}{|c|}{91,603} \\
\hline Birth state bonus & \multicolumn{4}{|c|}{57,328} \\
\hline \multicolumn{5}{|l|}{ Panel B: Percentage of Flow Earnings } \\
\hline \multicolumn{5}{|l|}{ Moving costs } \\
\hline Fixed cost of moving & -30.6 & -37.3 & -34.1 & -40.8 \\
\hline Average mover, 500-mile move & -101.9 & -112.8 & -107.5 & -118.7 \\
\hline $\begin{array}{l}\text { Average mover, New York to Los } \\
\text { Angeles }\end{array}$ & -147.5 & -160.8 & -154.4 & -168.0 \\
\hline $\begin{array}{l}\text { Young mover, New York to Los } \\
\text { Angeles }\end{array}$ & -116.9 & -128.0 & -122.6 & -134.0 \\
\hline \multicolumn{5}{|l|}{ Amenities } \\
\hline Std. Dev. of local amenities & \multicolumn{4}{|c|}{7.7} \\
\hline Range of local amenities & \multicolumn{4}{|c|}{30.2} \\
\hline Birth state bonus & \multicolumn{4}{|c|}{18.9} \\
\hline
\end{tabular}

Notes: Panel A expresses the monetary values in terms of net present value, while Panel B expresses monetary values in terms of the percentage of flow earnings. All results are derived from the parameter estimates in Table 6. The average mover is age 39, and a young mover is age 25. The great-circle distance from New York to Los Angeles is 2,446 miles. For complete details on how these values are calculated, see Online Appendix Section A.4. 
Table 8: Model fit: observed vs. predicted migration probabilities

(a) Migration probabilities by calendar time and $t-1$ employment status

\begin{tabular}{|c|c|c|c|c|c|c|}
\hline \multirow[b]{2}{*}{$t-1$ Employment status } & \multicolumn{2}{|c|}{ 2004-2008 } & \multicolumn{2}{|c|}{ 2009-2013 } & \multicolumn{2}{|c|}{ All } \\
\hline & Data & Model & Data & Model & Data & Model \\
\hline Emp & .30 & 1.3 & $1.28 \%$ & $1.24 \%$ & $1.29 \%$ & $1.29 \%$ \\
\hline Unen & $1.21 \%$ & 1.2 & $1.15 \%$ & $1.10 \%$ & $1.19 \%$ & $1.19 \%$ \\
\hline Out of labor force & $1.88 \%$ & $1.73 \%$ & $1.52 \%$ & $1.66 \%$ & $1.69 \%$ & $1.70 \%$ \\
\hline Overall & $1.14 \%$ & $1.27 \%$ & $1.38 \%$ & $1.22 \%$ & $1.25 \%$ & $1.25 \%$ \\
\hline
\end{tabular}

(b)

Migration probabilities by age and $t-1$ employment status

\begin{tabular}{lcccccccc}
\hline & \multicolumn{2}{c}{ Employed } & \multicolumn{2}{c}{ Unemployed } & \multicolumn{2}{c}{ Out of LF } & \multicolumn{2}{c}{ All } \\
\hline Age range & Data & Model & Data & Model & Data & Model & Data & Model \\
\hline $18-25$ & $2.31 \%$ & $2.11 \%$ & $2.54 \%$ & $3.62 \%$ & $3.37 \%$ & $3.31 \%$ & $2.52 \%$ & $2.84 \%$ \\
$26-35$ & $1.90 \%$ & $1.65 \%$ & $2.31 \%$ & $2.32 \%$ & $1.97 \%$ & $2.13 \%$ & $2.00 \%$ & $1.86 \%$ \\
$36-45$ & $1.00 \%$ & $1.20 \%$ & $1.57 \%$ & $1.42 \%$ & $1.23 \%$ & $1.30 \%$ & $1.13 \%$ & $1.25 \%$ \\
$46-55$ & $0.80 \%$ & $0.82 \%$ & $1.09 \%$ & $0.85 \%$ & $0.88 \%$ & $0.84 \%$ & $0.86 \%$ & $0.83 \%$ \\
\hline
\end{tabular}

(c)

Migration probabilities by distance migrated and $t-1$ employment status

\begin{tabular}{lcccccccc}
\hline & \multicolumn{2}{c}{ Employed } & \multicolumn{2}{c}{ Unemployed } & \multicolumn{2}{c}{ Out of LF } & \multicolumn{2}{c}{ All } \\
\hline Distance (miles) & Data & Model & Data & Model & Data & Model & Data & Model \\
\hline $0-500$ & $0.72 \%$ & $0.70 \%$ & $0.68 \%$ & $0.65 \%$ & $0.92 \%$ & $0.94 \%$ & $0.72 \%$ & $0.70 \%$ \\
$501-1,000$ & $0.31 \%$ & $0.35 \%$ & $0.29 \%$ & $0.33 \%$ & $0.41 \%$ & $0.45 \%$ & $0.31 \%$ & $0.35 \%$ \\
$1,001-1,500$ & $0.13 \%$ & $0.13 \%$ & $0.10 \%$ & $0.12 \%$ & $0.20 \%$ & $0.17 \%$ & $0.13 \%$ & $0.13 \%$ \\
$1,501-2,000$ & $0.07 \%$ & $0.05 \%$ & $0.06 \%$ & $0.05 \%$ & $0.11 \%$ & $0.07 \%$ & $0.07 \%$ & $0.05 \%$ \\
$2,001+$ & $0.06 \%$ & $0.05 \%$ & $0.07 \%$ & $0.04 \%$ & $0.05 \%$ & $0.06 \%$ & $0.06 \%$ & $0.05 \%$ \\
\hline
\end{tabular}

Notes: All numbers in this table correspond to migration probabilities (multiplied by 100 and expressed as percentages). Data probabilities consist of conditional means of an indicator for migration. Model probabilities consist of conditional means of the predicted probability of leaving the current location. 
Table 9: Model fit: employment transitions by migration status

(a) Employment transitions conditional on migrating

Period $t$

\begin{tabular}{lccccccc}
\hline & \multicolumn{3}{c}{ Data } & & \multicolumn{3}{c}{ Model } \\
\cline { 2 - 5 } \cline { 6 - 8 } Period $t-1$ & $E$ & $U$ & $N$ & & $E$ & $U$ & $N$ \\
\hline Employed $(E)$ & $70.98 \%$ & $22.69 \%$ & $6.33 \%$ & & $71.99 \%$ & $22.26 \%$ & $5.75 \%$ \\
Unemployed $(U)$ & $41.40 \%$ & $46.50 \%$ & $12.10 \%$ & & $45.06 \%$ & $44.77 \%$ & $10.17 \%$ \\
Out of labor force $(N)$ & $16.52 \%$ & $17.39 \%$ & $66.09 \%$ & & $13.88 \%$ & $12.58 \%$ & $73.54 \%$ \\
\hline
\end{tabular}

(b) Employment transitions conditional on staying

Period $t$

\begin{tabular}{lccccccc}
\hline & \multicolumn{3}{c}{ Data } & & \multicolumn{3}{c}{ Model } \\
\cline { 2 - 4 } \cline { 6 - 8 } Period $t-1$ & $E$ & $U$ & $N$ & & $E$ & $U$ & $N$ \\
\hline Employed $(E)$ & $86.92 \%$ & $9.86 \%$ & $3.23 \%$ & & $86.45 \%$ & $9.83 \%$ & $3.71 \%$ \\
Unemployed $(U)$ & $36.33 \%$ & $49.75 \%$ & $13.93 \%$ & & $38.09 \%$ & $49.60 \%$ & $12.31 \%$ \\
Out of labor force $(N)$ & $10.81 \%$ & $10.41 \%$ & $78.78 \%$ & & $10.56 \%$ & $12.22 \%$ & $77.21 \%$ \\
\hline
\end{tabular}

Notes: All numbers in this table correspond to employment transition probabilities (multiplied by 100 and expressed as percentages). Data probabilities consist of conditional means of employment transition by migration status. Model probabilities consist of conditional means (by employment status) of the predicted conditional probability of making an employment transition (conditional on leaving or staying). 
Figure 1: Annual migration rates by lagged employment status and migration distance

(a) Employed

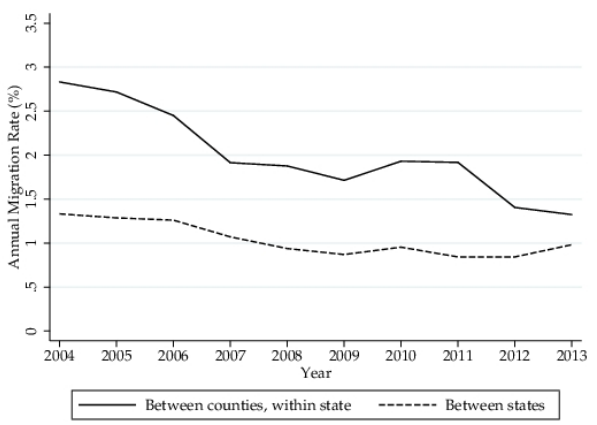

(b) Non-employed

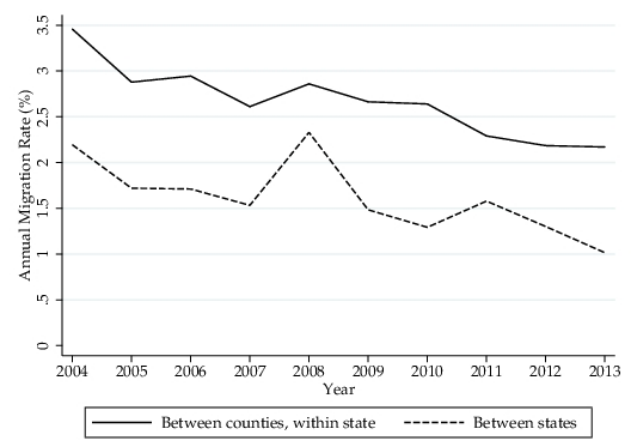

Source: 2004 and 2008 Panels of the public-use Survey of Income and Program Participation. Figures include all non-college graduates aged 18-55 who have completed their schooling. Employment is defined as full-time employment. 
Figure 2: Counterfactual changes in migration by origin city, prior employment status, and unobserved worker type

(a) High amenities, Type 1

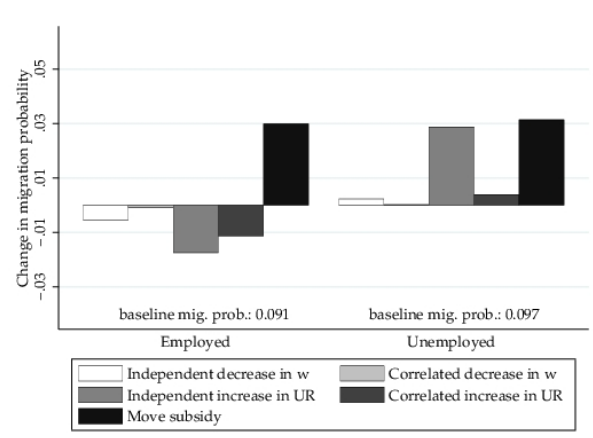

(c) High amenities, Type 2

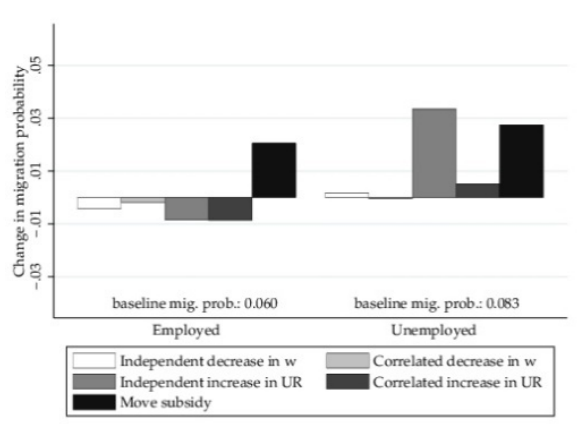

(b) Low amenities, Type 1

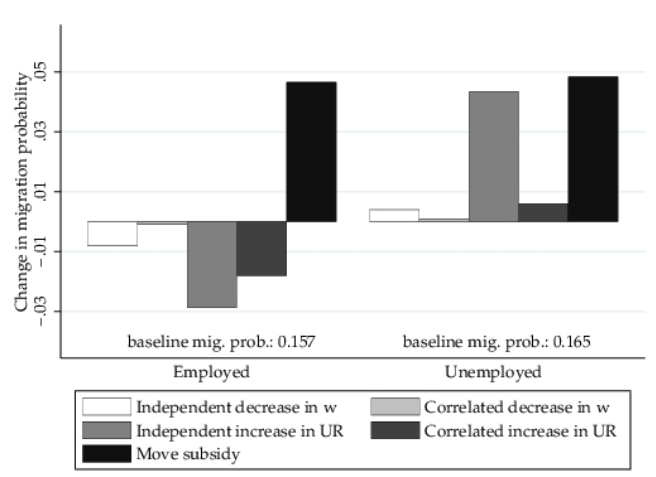

(d) Low amenities, Type 2

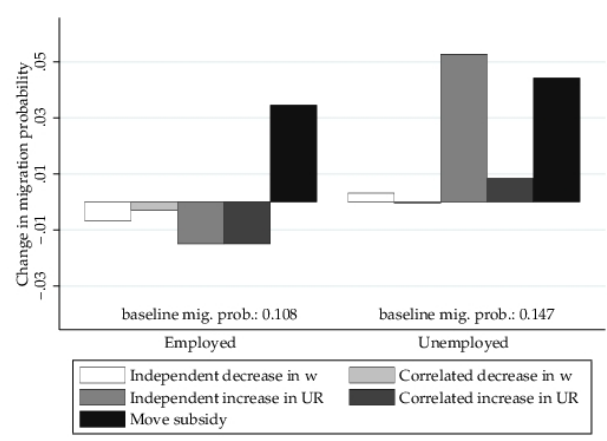

Notes: Each panel corresponds to a different origin city and unobserved type. Bar heights refer to the change in the out-migration rate from the specified location in response to the listed counterfactual. All figures are for 25 -year-olds who were not born in the origin location. "high" refers to a location in the 75th percentile of the given distribution; "low" refers to the 25th percentile. All characteristics not set to "high" or "low" are set to the median. The earnings shock $(\downarrow w)$ corresponds to the 70th percentile of the cross-location distribution in earnings AR(1) shock deviations. The unemployment shock corresponds to the jump from 2008 to 2009 for the average location in the data. To focus the results, each candidate location has median AR(1) parameters for both earnings and employment. Birth location is held fixed in all counterfactuals. Individual characteristics are set to the average for all 25 -year-olds, conditional on employment status. 
${ }^{i}$ Geography is an important part of monopsony power. See Bhaskar and To (1999); Bhaskar, Manning, and To (2002); Bhaskar and To (2003); and Staiger, Spetz, and Phibbs (2010) who examine multi-firm monopsony power through the lens of the canonical spatial models of Hotelling (1929) and Salop (1979).

ii See also Gould (2007); Kennan and Walker (2011); Baum-Snow and Pavan (2012); Bishop (2012); Coate (2013); Mangum (2015); Bartik (2018); Schluter and

Wilemme (2018); and Schmutz and Sidibé (2019) who estimate dynamic models of migration.

iii For other papers examining migration as adjustment to labor market shocks, see Sastry and Gregory (2014); Yagan (2014); Gardner and Hendrickson (2018);

Huttunen, Møen, and Salvanes (2018); Monras (2018); Foote, Grosz, and Stevens (2019); and Notowidigdo (2020).

iv See also Schmutz and Sidibé (2019) and Schlottmann and Herzog (1981) who find similar results in other contexts (France and USA, respectively).

$\checkmark$ This paper abstracts from industry and occupational choice. For a treatment of industry and occupation switching costs, see Bartik (2018). For an examination of oligopsony by occupation, see Handwerker and Dey (2019).

vi See also Marinescu and Rathelot (2018) who find that relocating job seekers to minimize unemployment would have only modest effects on the aggregate unemployment rate. Caliendo, Künn, and Mahlstedt (2017) find that mobility assistance programs in Germany increase geographical mobility of the unemployed. ${ }^{\text {vii }}$ For more information regarding the SIPP, see http://www.census.gov/sipp/. For more information about conducting research using confidential data in an RDC, see https://www.census.gov/fsrdc.

viii My definition of city is the Core Based Statistical Area (CBSA) as defined in 2009 by the U.S. Office of Management and Budget (OMB). CBSAs include one or more counties and are defined according to commuting ties. As such, they are a reasonable measure of whether or not a county belongs to a city. Using the 2009 definition, there are a total of 942 CBSAs-366 Metropolitan Statistical Areas (MSAs) and 576 Micropolitan Statistical Areas ( $\mu$ SAs). Because it is infeasible to estimate a model with this many locations, the choice set is aggregated.

ix See, for example, Moretti (2012) who contrasts the labor market trajectories of different areas within California.

${ }^{x}$ See https://en.wikipedia.org/wiki/List_of_core-based_statistical_areas.

${ }^{x i}$ For the 20 residual locations, unemployment is aggregated to the location level.

xii Studies using this data include: Glaeser and Maré (2001); Kennan and Walker (2011); and Baum-Snow and Pavan (2012), among others.

xiii See Kennan and Walker (2011), Bishop (2012), Bartik (2018) and Wilson (Forthcoming, Forthcoming) for other migration studies that focus on a similar demographic group.

xiv The main result from Figure 1 also holds for a more conventional definition of employment and labor force participation (see Online Appendix Figure A2) as well as for other demographic sub-groups (see Online Appendix Figure A3).

xv These findings can be replicated in other survey data from the US, such as the National Longitudinal Survey of Youth or the American Community Survey. They also hold for more conventional definitions of labor force participation and employment, as well as for other demographic groups (see Online Appendix Tables A6 and A7)

xvi Additionally, Amior and Manning (2018) argue that local labor supply ratios are key indicators for individuals' economic opportunity.

xvii The model relates to Molloy and Wozniak (2011), who examine migration over the business cycle. In my model, individuals are assumed to know what each location's labor market conditions are, as well as their trends and persistence. See also Wilson (Forthcoming), who details the role of information on migration decisions.

xviii These conditions include additive separability of the flow utility covariates and preference shocks, and conditional independence of the state variables and preference shocks.

xix Individuals are also assumed to know the function $F$ that characterizes the distribution of state transitions. This allows individuals to integrate over future state realizations.

${ }^{x x}$ The earnings model has 544 parameters, the employment probability models have 120 parameters, the parameters of the choice model-amenities and moving/switching costs - number 72, and the local labor market forecasting model has 276 parameters.

${ }^{x x i}$ See Kennan and Walker (2011) and Arcidiacono et al. (2016) who also impose this assumption, although the former study specifies expected earnings in levels rather than logs.

xxii The standard assumptions include linearity of the model's parameters, additive separability of the error terms, and distributional assumptions on the error terms.

xxiii One would more easily be able to interpret what characteristics the "high type" individuals possess if there were additional data available. For example, 
cognitive test scores could be linked to the unobserved type to aid in interpretation. Unfortunately, the SIPP has very limited information on cognitive skills and I am not able to include this in the model.

xxiv For computational reasons, I restrict the number of types to be two.

${ }^{\mathrm{xxv}}$ The 20 percentage point difference comes from evaluating the logistic function at the estimated parameter values and 0 years of experience, separately for movers and stayers.

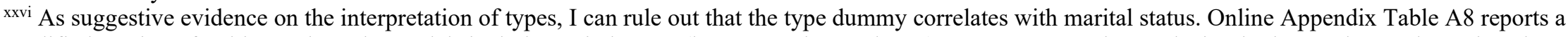
modified version of Table 4, where the models include marital status (but not unobserved type) as a regressor. The results imply that unobserved type is only weakly correlated with marital status, because the results in the "Control for marital status" supercolumn are closer to the " 1 type" results in Table 4 than they are to the "2 types" results in Table 4. More likely, the type dummy captures persistent unobservables such as cognitive and non-cognitive skills.

xxvii For example, the positive coefficient on expected log earnings indicates that cross-location differences in earnings matter to migration decisions, as found by Kennan and Walker (2011) and others. Individuals value locations that are in their state of birth, more than for locations in their Census division of birth (Diamond, 2016). Fixed costs of moving are substantial, but also steeply increase with distance and age (Bishop, 2012).

xxviii Other papers estimating moving costs include Bayer, Keohane, and Timmins (2009); Morten and Oliveira (2016); Diamond (2016) and Shenoy (2016). Exact values of moving costs depend on assumptions of the underlying model, including whether the model is static or dynamic.

xxix Allowing the individual to choose the best available location would substantially reduce this cost. Kennan and Walker (2011) also show that the moving cost for actual moves is much lower than for the average mover. A similar line of logic applies to the current model, but I omit the discussion here for expositional purposes. ${ }^{\mathrm{xxx}}$ Additional results for four other artificial cities and for unemployment and labor supply responses are included in the Online Appendix. The six locations

correspond to three pairs of artificial cities, each possessing characteristics at specific points in the respective distribution of city characteristics for local amenities, earnings, and employment probabilities. For example, I calculate the difference in the probability of out-migration with and without the policy in a city at the 75 th percentile of the amenities distribution versus a city at the 25 th percentile of the amenities distribution. All other city characteristics are identical across the two cities. In all cases, the artificial city is set to be in the same geographical location. The exact geographical location of the artificial city makes little difference to the final results. This process is repeated for earnings and employment probabilities. Constructing the counterfactuals in this way allows me to hold fixed city characteristics, which turn out to be important determinants of migration behavior (Coate and Mangum, 2019).

xxxi The degree of spatial correlation is that implied by the correlation of the residuals in the system of autocorrelation equations.

xxxii These migration rates are heterogeneous across cities, employment status, and type. In particular, predicted outmigration is highest for the city with the lowest amenities, and for those who are type 1 . In contrast, out-migration is smallest for the city with high amenities and those who are type 2 . These results point to the importance of considering amenities when forming policy that is intended to affect migration behavior. The baseline migration rates also differ markedly by employment status. The rate of out-migration for unemployed workers is 1.2 to 1.5 times the rate for employed workers, consistent with the stylized facts presented in Figure 1. However, there is substantial heterogeneity across cities and unobserved worker types.

xxxiii The earnings shock corresponds to the 70th percentile of the cross-location distribution in earnings AR(1) shock deviations. The unemployment shock corresponds to the 2008-2009 increase in the local unemployment rate for the average location in the data.

xxxiv These findings contrast with those of Gardner and Hendrickson (2018), who show that labor markets with higher variance in unemployment rates have lower out-migration rates, all else equal. My approach underscores that moving incentives differ drastically by employment status.

${ }^{x x x v}$ There is also substantial heterogeneity in migration responses to local economic shocks with respect to unobserved type. For example, employed type 1 workers are more likely than type 2 workers to stay in response to each of the four shocks. This is because type 2 workers have a comparative advantage in job finding, and employed movers are much less likely to find a job upon arrival in a new location. The comparative advantage of type 2 workers also explains why unemployed type 2 workers are more likely than unemployed type 1 workers to leave in response to an unemployment shock. This is true even though type 2 individuals have larger moving costs.

xxxvi There is also heterogeneity in the moving subsidy response. The increase is largest in areas with low amenities. Unemployed workers are more responsive to each subsidy, even though they have larger moving costs. The reason ties back to the fact that unemployed movers do not face an employment penalty. Finally, type 2 workers are more likely to stay because their moving costs are higher. 